\section{Shift in position of a pulmonary coin lesion after percutaneous biopsy}

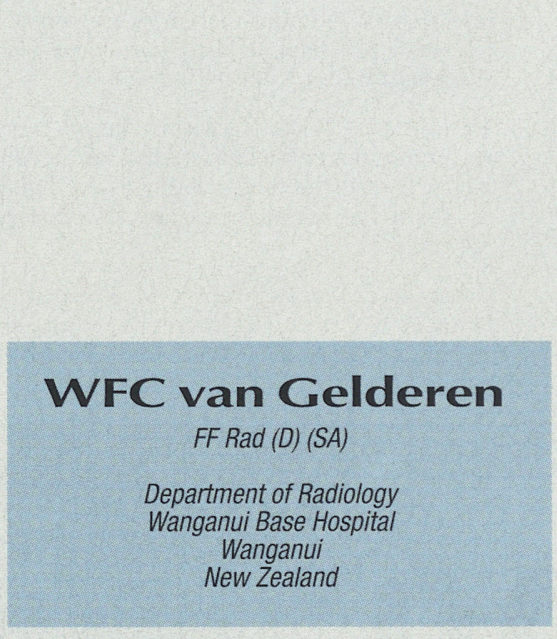

Abstract

An unusual phenomenon is

detailed where a malignant coin

lesion in the chest shifted in

position after percutaneous lung

biopsy and the possible causes of

this uncommon event are

postulated.

\section{Case report}

A 66 year-old man was referred for chest radiographs one year after total laryngectomy for squamous cell car-

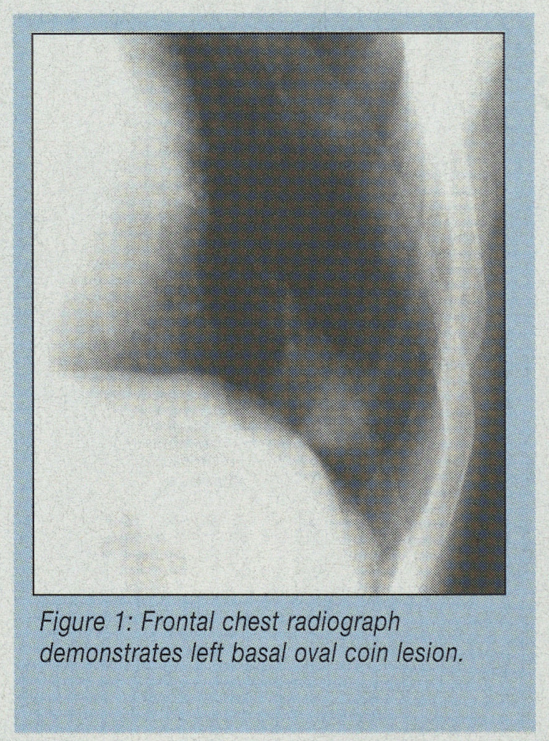

cinoma of the larynx, which revealed a small opacity at the base of the left lung (Figure 1). Subsequent computed tomography (CT) confirmed a $2.5 \times 1.7 \mathrm{~cm}$ lobulated coin lesion of homogeneous soft tissue density in the anterior basal segment of the left lower lobe closely related to the posterior surface of the lower end of the major fissure.

Percutaneous lung biopsy under CT guidance (Figure 2) with a 20 gauge biopsy gun was attempted via an anterior approach and a small tissue sample was obtained during the second pass. There was a significant post-biopsy pneumothorax which resolved with conservative management and the patient made an uneventful recovery.

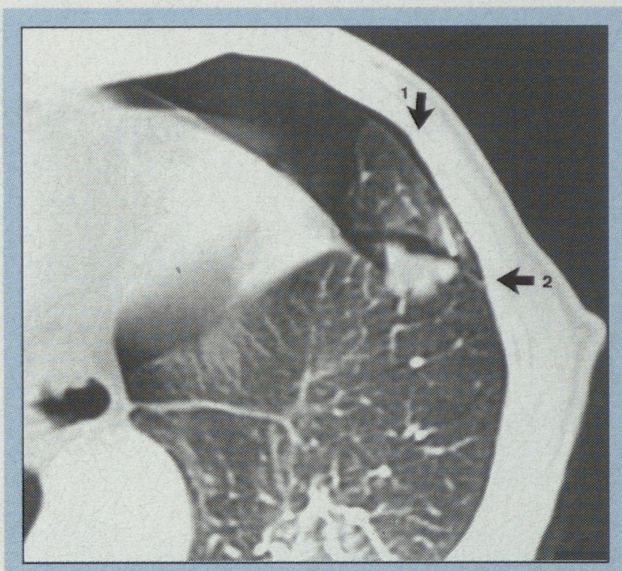

Figure 2: Subsequent CT shows the lobulated coin lesion in the anterior basal segment of the left lower lobe immediately posterior to the major fissure and close to the chest wall. Percutaneous biopsy was performed via an anterior approach traversing the fissure and resulted in a significant pneumothorax. The tip of the biopsy gun needle is noted antero-lateral to the coin lesion at the time of the second pass. [Arrow (1) indicates direction of initial biopsy with biopsy gun]. Subsequent fine needle aspiration biopsy was performed one year later (at time of Figure 3) via lateral approach [arrow (2) indicates direction of needle.]

The biopsy sample was unfortunately not diagnostic.

Chest radiographs one year later again demonstrated the opacity which had increased slightly in size $(2.7 \times 2.0 \mathrm{~cm})$ but now was $15 \mathrm{~mm}$ more medial in position with its superomedial part rotated in a slightly inferior direction (Figure 3). CT revealed pleural thickening of the lateral aspect of the major fissure adjacent to the coin lesion and thin fibrotic lines were noted medial to the lesion.

A subsequent fine needle aspiration of the coin lesion under CT guidance was attempted via a lateral approach in the prone position so as not 


\section{Shift in position of a pulmonary coin lesion after percutaneous biopsy}

from page 18

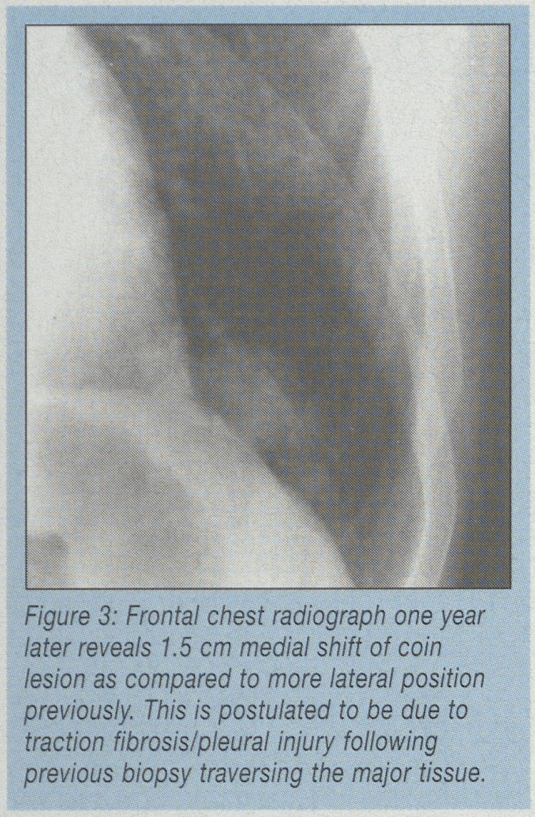

to traverse the major fissure and a satisfactory specimen was obtained with only a minimal post-biopsy pneumothorax. Pathologic examination revealed an adenocarcinoma, a left lower lobectomy was performed, and the patient made a satisfactory recovery.

\section{Discussion}

Whenever a percutaneous biopsy under radiologic guidance is considered, traversing a fissure should be avoided if at all possible. 'This rule was not adhered to on the first occasion, and was a possible contributing factor towards the development of a significant pneumothorax. It is postulated that traction fibrosis and pleural thickening may have resulted because of the transfissural approach and that this was the cause for the coin lesion having shifted in position on follow-up chest radiographs and $\mathrm{CT}$ one year later. This appearance was most baffling on chest radiographs initially, but it is thought that post-biopsy injury to the pulmonary parenchyma and/or pleural surfaces was responsible for the change in position of the malignant pulmonary lesion.

These short case notes were prompted by the fact that this phenomenon does not appear to have been recorded in the literature before, and on discussion with colleagues who do many percutaneous lung biopsies, it is interesting to note that none of them have ever come across such an appearance before. It does support the original contention that a transfissural approach should be avoided whenever possible, and depicts another possible consequence of this approach with quite considerable shift in the position of the coin lesion one year later.

\section{Reference}

1. Sider L. Percutaneous CT-guided biopsy of lung and mediastinal lesions. In: Kadir S. Current Practice of Interventional Radiology. Philadelphia: B.C. Decker Inc. 1991: 219-222.

\section{BOOK REVIEW}

\section{Title: Exercises in diagnostic imaging}

\section{Authors: \\ Burnett S and Saifuddin A \\ ISBN: \\ 90-5702-017-3}

\section{Date of publication:}

May 1997

\section{Publisher:}

Harwood Academic

Publishers

\section{Supplier:}

Marston Book Services,

$\mathrm{PO}$ Box 269, Abingdon,

Oxon OX14 4YN, United

Kingdom

\section{Cost:}

\pm R400.00 for hard cover

\pm R160.00 for paper

edition
The specific aim of this book is to provide practice for those candidates attempting the final fellowship examination of the College of Radiologists in London.

The format of the book is divided into 10 exercises and each exercise consists of eight different case studies. A brief history is given and the candidate is required to assess all the radiographs, which are of extremely good quality, and come to either a final or differential diagnosis. Answers are provided at the end of each exercise and potential candidates are advised not to take the simple route of quickly perusing the images and then checking the answers before proceeding with the next case.

Observational skills are sadly lacking in many of the candidates who present themselves for the higher radiological examination. This book goes a long way to improving those skills and it is a book that I would heartily recommend to any candidate who intends sitting a higher examination in radiology.

I would recommend that this book be available in each Department of Radiology and be extensively used by all potential candidates.

Joel H Bortz, Private Radiologist, Durban 